\title{
THE PATHOGENESIS OF THROMBOSIS
}

\author{
L. Poller, M.D. (Manch.) \\ Department of Clinical Pathology, Manchester Royal Infirmary
}

The pathogenesis of thrombosis has excited the curiosity and interest of clinicians and pathologists for a great many years. In modern times the ever-increasing incidence of thrombosis and embolism in Western countries has resulted in a vast amount of research into the problem. This has been directed along many channels, being based on clinical, laboratory, sociological and so-called ' epidemiological' studies. Thrombosis and the factors giving rise to it may be classified in a variety of ways. One of the most valuable classifications was provided as long ago as 1924 by Aschoff. ${ }^{3}$ The mechanisms leading to thrombus formation were classified under four headings on theoretical grounds. The first was changes in the coagulability of the blood, the second changes in the formed elements of the blood, the third changes in the circulatory blood flow and the last changes in the vessel walls.

The first problem which arises therefore is whether there is a demonstrable increase in coagulability in cases of recent thrombosis. Attempts have been made to show this by the use of blood coagulation time techniques. Fingerprick capillary clotting times, clotting times by venous method of Lee and White and modified methods employing non-wettable surfaces of lusteroid or silicone have been used in patients with thrombosis and parallel controls. In each case claims have been made that the method showed shortened clotting times in the thrombotic patients but in each and every instance later detailed studies were unable to substantiate the claim.

The use of the clotting time methods to demonstrate increased coagulability was based on two basic assumptions. The first was that a local predisposition to thrombus formation in a coronary or peripheral vessel would be associated with a general increase in coagulability of the entire blood registered at a point distant from the clot, and the second was that the methods in current use would be sensitive enough to measure these

A paper presented to Manchester Medical Sciences Colloquium on January 19, 1960. changes. The failure of the blood clotting times. to register increased coagulability was regarded $b \vec{b}$ some investigators not as evidence of its absence but of lack of sensitivity of these methods to the changes in recent thrombosis. A further tech? nique was evolved, therefore, which dependew upon the addition of an inhibitor of coagulation to clotting times to prolong the tests in the hope of detecting differences which might not have beers apparent before. The only method to be used on any large scale has been the addition of heparin to tests of clotting times.

The heparin tolerance test was introduced b the Canadians Waugh and Ruddick in $1944 .^{29}$ I was, in fact, a venous blood coagulation time method performed in nine separate tubes, th creasing amounts of heparin being added to the्क्ति It was thus possible to draw an in vitro hepasis tolerance curve for an individual. Claims were made that shortened clotting times (i.e. increased heparin tolerance) were present in cases of recens thrombosis. ${ }^{19}$ Later work, including a surve published from Oxford in $19533^{14}$ failed to substantiate this claim.

The trouble with the Waugh-Ruddick test wa that it was elaborate, was difficult to perform and took one to two hours to complete. Thus spon? taneous changes in coagulability which occup when blood is stored in glass tubes and which weres insufficiently appreciated at the time were $q$. source of error. The heparin plasma clotting times test $^{22}$ is a single tube test based on the heparin tolerance principle. Plasma was preferred to whole blood to improve the end-point and a standard preparation of heparin was used which has been found to be stable for several months? Using this method under standardized conditions? reproducible results were obtained. A normans range was divided from 100 healthy adults. A series of hospitalized patients without evidence of thrombosis was then observed as a control group. The results are given in Fig. I. The mear coagulation time was shorter than that of the normal group. In Fig. 2 are given the results in 64 cases of recent thrombosis tested within $48^{4}$ hours of onset. Here there was significant 


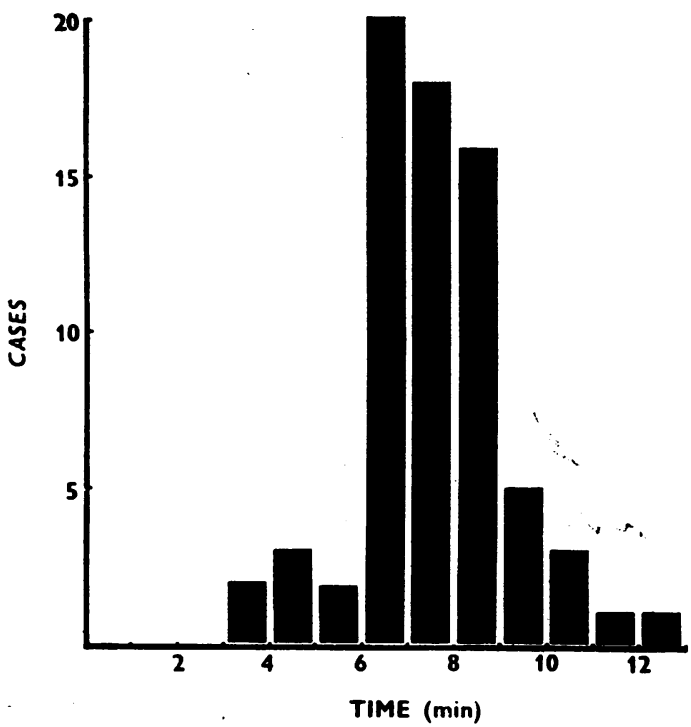

Fig. 1.-Heparin plasma clotting times in 71 cases with no evidence of thrombosis.

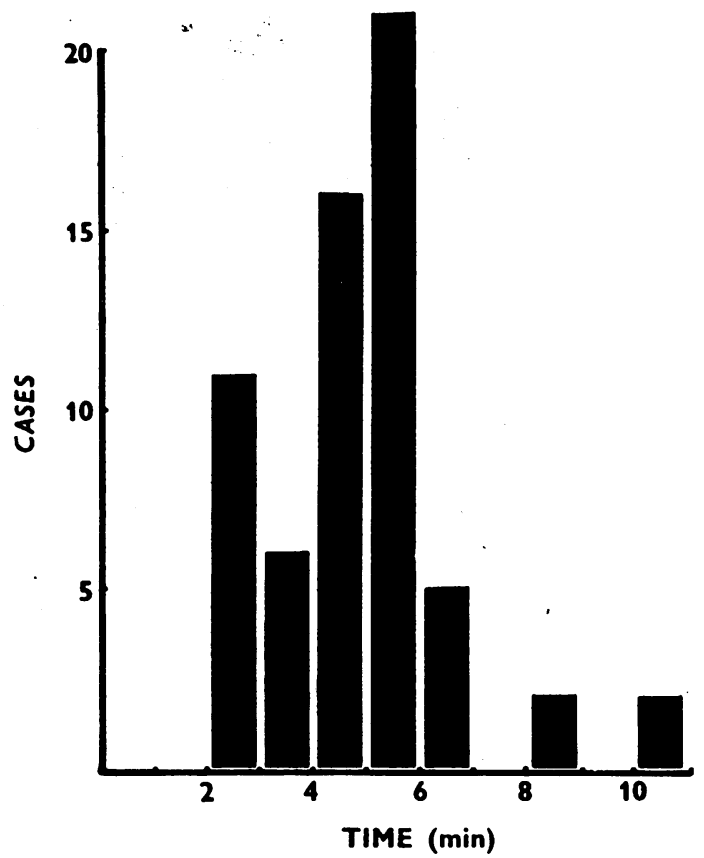

Fig. 2.-Results of heparin plasma clotting times in 64 cases of recent thrombosis.

shortening of the clotting time compared with the normal group and the group of patients in hospital without evidence of thrombosis. The distribution is somewhat uneven but this was not a homogeneous group. In fact the 17 cases of deep vein thrombosis included had a significantly shorter

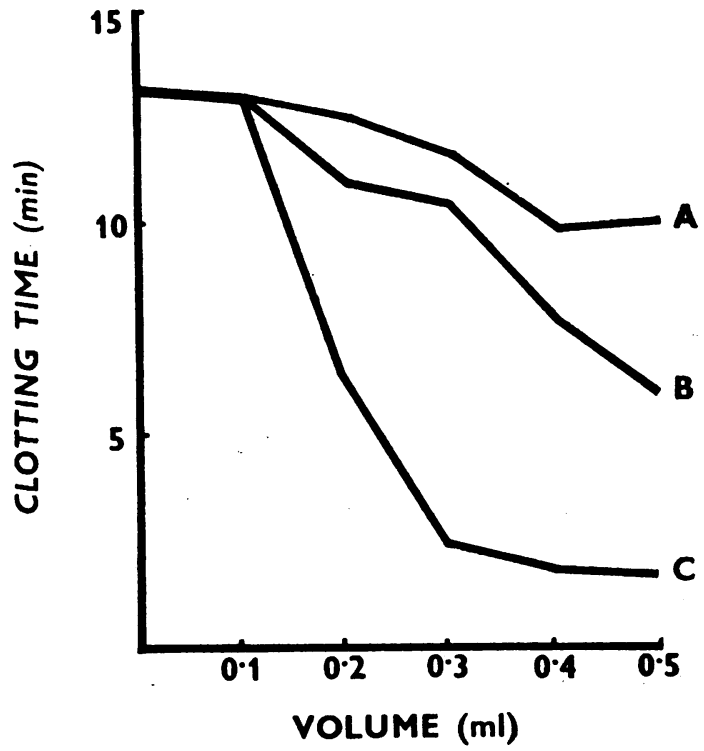

FIG. 3.-The effect of adding increasing volumes of stored normal serum (B), and serum products obtained by alumina adsorption and elution (C). Line (A) is the simple effect of dilution with normal saline, calcium being present in greater amounts than the optimum in the heparin plasma clotting mixture.

clotting time than the 34 cases of coronary thrombosis included in the series. This finding will be referred to later.

Does the demonstration of shortened heparin clotting times in cases of recent thrombosis mean that the presence of increased coagulability has been established? This has not been finally settled. It has been shown ${ }^{25}$ that normal stored serum reduces the anticoagulant effect of heparin on plasma clotting (Fig. 3). This activity is present in factor VII solutions prepared by the alumina-adsorption of serum but does not appear to depend on the presence of factor VII or of Christmas factor, or on the anti-heparin activity of platelets described by Van Creveld et al. ${ }^{5}$ An agent with similar physical properties has been found by Wessler and co-workers ${ }^{30}$ in the United States to be responsible for the production of thrombi in experimental animals. It thus appears possible that the shortened heparin clotting times may in fact be secondary to a formed thrombus, resulting from the release of serum products into the circulation. ${ }^{25}$ The fact that patients with large vessel occlusion had shorter clotting times than the patients with coronary thrombosis lends some support to this view.

With the lack of clear demonstration of increased coagulability using methods for the coagulation time of the blood, can more specific 


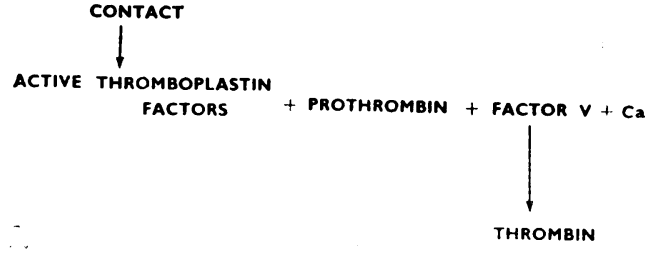

Fibrinogen $\longrightarrow$ fibrin
Fig. 4.-Simplified scheme for 'intrinsic' blood
coagulation.

methods demonstrate changes producing a hypercoagulable state? With increasing knowledge of the blood coagulation pattern obtained in recent years there has been a multiplication in the techniques available to us. Contact with a wettable surface activates the thromboplastin complex consisting of Hageman factor, P.T.A., Christmas factor, antihaemophilic globulin and Prower Stuart factor. These in the presence of prothrombin, factor $\mathrm{V}$, and calcium and perhaps accelerated by factor VII, produce thrombin. Thrombin is the enzyme responsible for the conversion of fibrinogen to the fibrin clot. A simple outline of this scheme is given in Fig. 4.

Prothrombin times were introduced by Quick in $1935{ }^{.27}$ since the administration of the anticoagulant drugs of the coumarin type became general medical practice in the late 19408 there has been an opportunity to observe large groups of patients with this technique. Although claims were made that the method showed shortened clotting times in thrombosis it is now accepted that this is not the case.

Prothrombin activity as measured by the Quick method is a complex of prothrombin, factor V, factor VII and Prower Stuart factor. Specific methods exist for these clotting factors. Interesting results were obtained with one of these methods, the specific assay of factor VII, in patients with thrombosis. ${ }^{24}$ It was found that the plasma of patients with recent thrombosis restored the clotting defect of factor VII deficient plasma more than controls. The results of the mean of 20 cases and 20 controls are given in Figs. 5 and 6. Some confirmation of these results has been given by Alexander, ${ }^{1}$ who found increased factor VII activity in some but not all cases of recent thrombosis.

The significance of raised factor VII activity in recent thrombosis is by no means clear. Factor VII is an accelerator of prothrombin conversion and it might be assumed that excess would be associated with increased coagulability. Indeed the demonstration of increased factor VII levels during pregnancy by several groups of investiga-

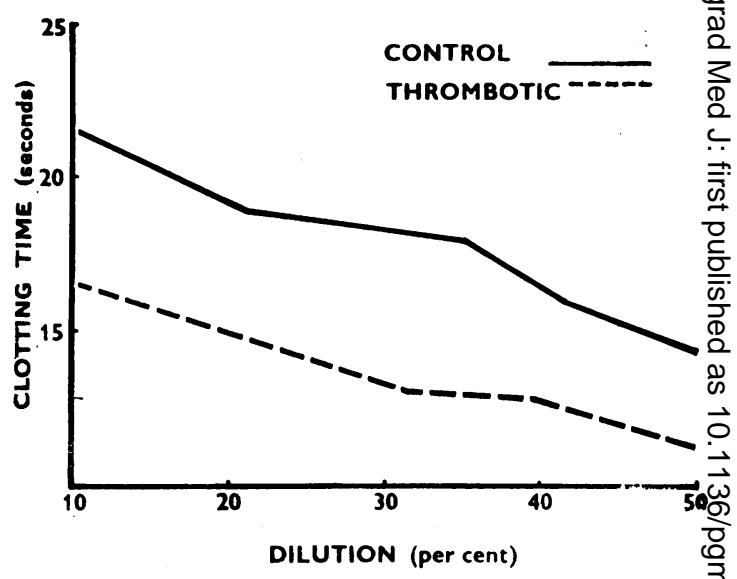
FIG. 5.-The effect of control plasma and thrombotic. VII deficient plasma.

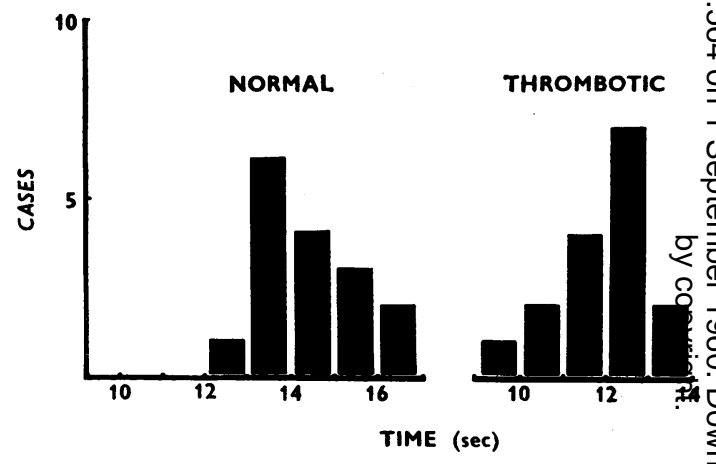

FIG. 6.-Factor VII levels. Distribution of readings of $50 \%$ dilutions in thrombosis and controls

tors has been taken as evidence of the hyper $\overrightarrow{\vec{\sigma}}$ coagulable state associated with pregnancy. Factor VII is not consumed during clotting but is activated, excess being present in serum. It is. possible, therefore, in this instance also that excess is due to the release of serum products into the circulation.

The thromboplastin generation test was in troduced by Biggs and Douglas. ${ }^{4}$ This test was used by Poller in investigations comparing throm? botic patients with controls. It was noted that thromboplastin generation appeared to be in creased in the cases of recent thrombosis. ${ }^{24}$ I the same year McDonald and Edgilli ${ }^{17}$ foungs thromboplastin generation to be increased ip ischaemic heart disease, and later McDonald 10 showed also that thromboplastin generation was ine creased in cases of recent coronary thrombosis The association of increased factor VII activite together with increased thromboplastin generatio and shortened heparin clotting times is of interest, as it is now well established that factor VII is no? 


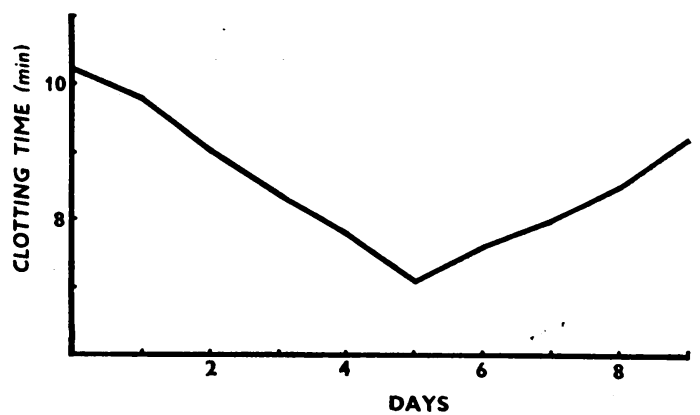

FIG. 7.-Heparin plasma clotting times after operation.

involved in blood thromboplastin generation. There is evidence, therefore, of a combined coagulation anomaly in recent thrombosis.

We cannot leave the subject of coagulability and thrombosis without reference to post-operative coagulability. There is a well-established relationship between surgical operations and a thrombotic tendency. The risk varies in the surveys reported, but it is higher in major abdominal and pelvic operations. Coagulability studies were performed with the heparin plasma clotting time, in a group of 40 patients undergoing a variety of common operations. The maximum fall of clotting time during the ro days after operation is seen (Fig. 7) to occur on the fifth day after operation. This is somewhat surprising, as it is often stated that the maximum incidence of thrombus formation occurs several days later. Two other surveys by Allen et $a l .{ }^{2}$ and Gardikas et al. ${ }^{9}$ have confirmed that the shortest clotting times occur on the fifth day after operation. Payling Wright ${ }^{21}$ has reviewed the problem and has noted that a maximum increase in fibrinogen, platelet 'stickiness' and slowing of the foot-groin venous flow time occur together at about the tenth day after operation, which is the time of the greatest incidence of thrombosis. It is thus possible that the coagulability changes may not be of prime importance in the causation of post-operative thrombosis, although this view is opposed by Gardikas et al. ${ }^{9}$

Clinical thrombosis tends to be episodic in character, the most notorious form being 'thrombosis migrans'. Other forms of the disease may show this tendency to a lesser extent. There is some evidence from coagulability studies which helps to explain this phenomenon. The heparin plasma clotting test was introduced in 1952 as a method for the better control of anticoagulant therapy, as it was felt that control by Quick prothrombin times was not sufficiently safe, thrombosis and haemorrhage on occasion being present at 'safe' levels. It was thought necessary to include two control groups. The first was a group of hospital patients without evidence of thrombosis

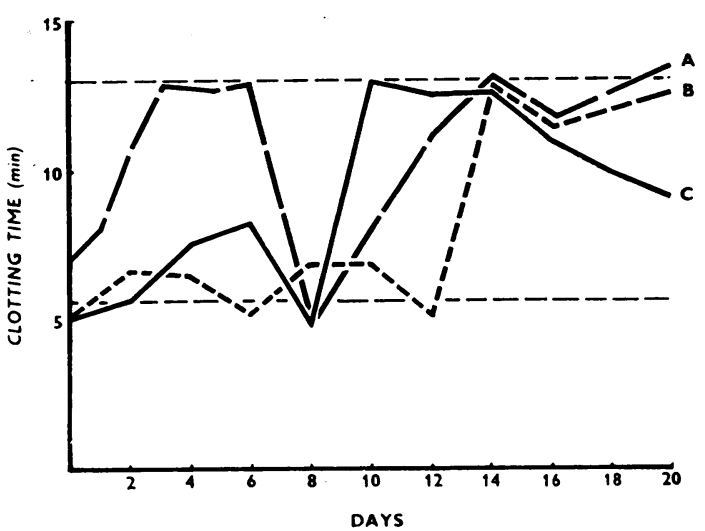

FIG. 8.-Spontaneous changes in clotting times in three cases of coronary thrombosis.
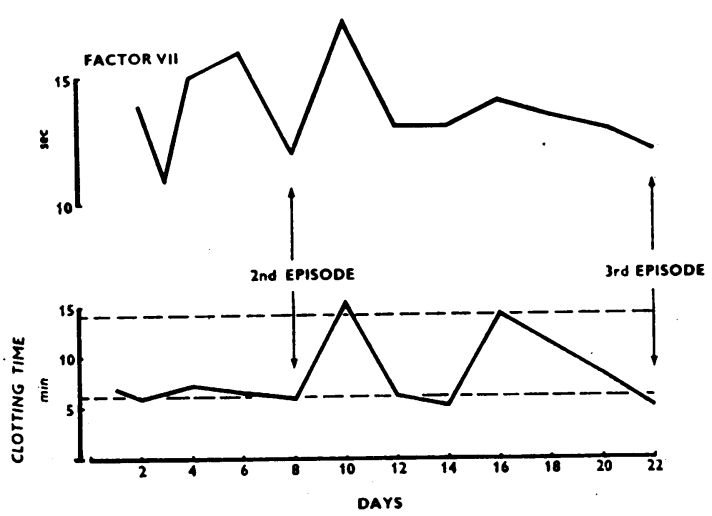

Fig. 9.-Spontaneous changes in clotting times and factor VII in coronary thrombosis.

on whom clotting times were performed, at similar periods to the patients on treatment. The second control group consisted of 20 patients with recent thrombosis who did not receive anticoagulant drugs. As was hoped, the controls without thrombosis were stable from day to day, without much variation in any case. The results in the thrombotic controls were completely different, however, shortened clotting times being present initially but followed by a period of reduced coagulability after two to three days which in some cases appeared to amount to a definite coagulation defect. There was then a tendency to return to normal over a period of several days and in several cases the return of shortened clotting times was associated with a further thrombotic episode. This fluctuating pattern was present in varying degree in all the thrombotic group. The patterns of three typical patients suffering from coronary thrombosis are illustrated (Fig. 8).

Is there any more evidence to support the existence of these fluctuations of coagulability? 


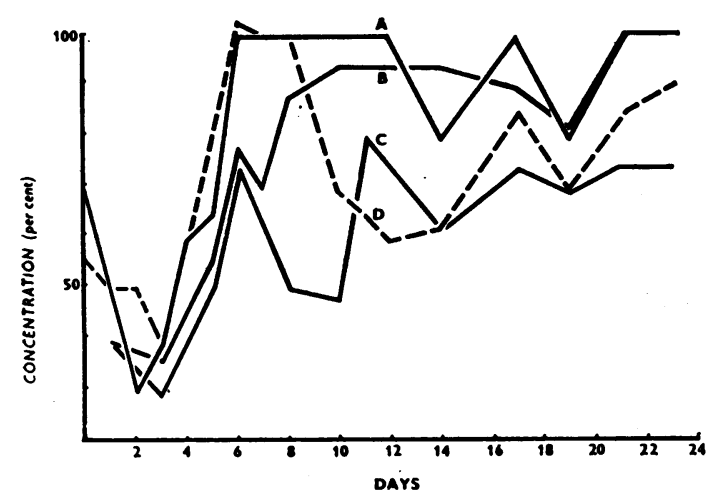

FIG. ro.- Spontaneous changes in coagulability in a case of myocardial infarction.

A. Quick's prothrombin time.

B. Owren's P. and P. method.

C. Thrombotest.

D. Thromboplastin generation test.

It is well known that some patients are more sensitive in the early days of anticoagulant treatment than later on and unexplained fluctuations occur. In Fig. 9 are the heparin clotting times and factor VII levels of a case of coronary thrombosis who had two further episodes of myocardial infarction. A fluctuating pattern is present in both and the further episodes came when both factor VII levels were increased and heparin clotting times fell below the lower limit of normal.

During observations on thromboplastin generation in patients on phenindione treatment it was noted that a fair proportion of subjects had patterns of thromboplastin generation which did not appear to have a close relationship to either the dosage of the drug or the level of prothrombin activity. ${ }^{15}$ The patterns bore a striking resemblance to the coagulability patterns with the heparin clotting time in untreated thrombosis. This pattern of thromboplastin generation was not present in patients without thrombosis. In Fig. Io there is a striking picture. This case of myocardial infarction developed a marked coagulation defect two to three days after the clinical onset. This observed defect was present in four different coagulation techniques, the Quick prothrombin time, Owren's P. and P. method, the thromboplastin generation test and the 'thrombotest'. The thrombotest is a new technique devised by Owren $^{20}$ for the better control of anticoagulant treatment. It has been under trial at Manchester Royal Infirmary and the indications from the investigation are that it is a useful index of coagulability. ${ }^{15}$ All four methods show in varying degree the fluctuating coagulation pattern, which is similar to that previously observed with the heparin plasma times. If these changes are commonly present in untreated thrombosis they appear of importance not only in relation to the evolution of the disease but in connection with the $\frac{3}{0}$ laboratory control and dosage of anticoagulant $\varrho$ treatment.

The changes in the formed elements of the blood $\overrightarrow{\vec{S}}$ is the second of Aschoff's theoretical mechanisms -0 of thrombus production. Of the changes in the red cells both anaemia and poylcythaemia are $\overline{\bar{c}}$ associated with a clotting tendency. The platelets $\mathbb{\square}$ have been intensively studied in view of their known role in haemostasis. Increased platelet ${ }^{\infty}$ 'stickiness' has been found in the thrombotic $\vec{O}$ state by several authors in recent years, e.g. $\overrightarrow{\vec{H}}$ Spooner et al. ${ }^{28}$.

Changes in the circulatory dynamics have been insufficiently studied owing to the difficulty of 3 simulating the events in the body in test tube experiments. Circulatory slowing is associated with the post-operative state and occurs after bed $\overrightarrow{0}$ rest, both of which are associated with a pre- ir disposition to thrombosis. When blood clotting $\stackrel{P}{\perp}$ times are performed in silicone tubes, a firm solid 음 clot results after some delay. The result when the silicone tube is put in a suspension mixer instead $\Phi$ of a stationary rack is completely different, how- $\frac{\mathbb{O}}{0}$ ever. The mixer rotates slowly at 30 revolutions $\frac{\mathbb{D}}{3}$ per minute and imparts a continuous to-and-fro motion to the blood. Under these conditions \& solid clot never forms, but clotting takes the for $\vec{\varphi}$ of the deposition of a firm web of fibrin on the wat? of the tube. If a tube were removed after one hour a small solid $\operatorname{clot}^{-}$formed in addition, but after 24 hours no solid clot formed. Related to the events in an elastic artery, this suggests that the circulatory dynamics may govern the nature of the $\frac{\circ}{\mathbb{Q}}$ resulting clot. A solid clot may, therefore, only $\overrightarrow{\overrightarrow{\vec{P}}}$ form when the circulation is slowed or arrested; $\frac{0}{3}$ where there is a good circulatory flow, clotting may take the form of the deposition of fibrin on the walls of a vessel which supports Duguid's thrombogenic theory of atherosclerosis. ${ }^{26}$

This brings us to the fourth of Aschoff's mechanisms, the changes in blood vessel walls. Damage, disease, and inflammation predispose to 8 intravascular clotting. The anatomical association between atherosclerosis and thrombosis has long 0 been recognized. Duguid ${ }^{8}$ revived Rokitansky's theory that atherosclerosis resulted from the organization of clots. Histological evidence and experimental evidence for this is derived from the $\mathrm{N}$ injection of fibrin particles into rabbits. ${ }^{11,13}$ In $N$ Duguid's view, atherosclerosis formation and N thrombosis are part of one single pathological $\sigma$ process. There are difficulties in the unreserved acceptance of this theory as far as coronary $\frac{D}{\mathbb{D}}$ thrombosis is concerned.

There has been a vast amount of research in 0 recent years on the part played by fats in blood 
coagulation and thrombosis. This has been based on dietetic surveys, sociological, clinical and laboratory studies. The effects of fats have been studied on clotting in vitro and the effects of fatty meals in the human subject by numerous authors. The association between abnormal lipoproteins and a predisposition to thrombosis has been studied.6,10 From the vast amount of evidence accumulated it appears that fat and particularly animal fat may play some part in the predisposition to thrombosis as well as to atherosclerosis formation, although the extent of this is not yet defined.

Other considerations in relation to thrombosis should be mentioned for the sake of completeness, although it would be out of place to consider them in detail in this survey devoted primarily to laboratory studies. Thrombosis is associated with certain clinical states, e.g. diabetes, hypertension, xanthomatosis and malignancy. It is also associated with a familial or racial tendency. From surveys it appears that cigarette smoking may predispose to thrombus formation. ${ }^{7,12}$ Insufficient physical exercise may also play a part as suggested by the occupational survey in London Transport workers by Morris. ${ }^{18}$

Thus a multiplicity of factors and influences are involved in the pathogenesis of thrombosis. Coagulability studies appear to be of importance, as do changes in the circulatory blood flow from the scanty evidence available. The extent of the role played by fats is not yet finally decided. Further research may result in the discovery of a 'trigger mechanism'. It is much more likely, however, that it will confirm the need to consider many different causes and influences in the problem of intravascular clotting.

\section{REFERENCES}

I. ALEXANDER, B. (1959), New Engl. F. Med., 260, 1288.

2. ALLEN, G. W., and ATTYAH, A. M. (1953), f. Lab. clin. Med., 41, 767 .

3. ASCHOFF, L. (1924), 'Lectures in Pathology', Paul B. Hoeber Inc., New York.

4. BIGGS, R., and DOUGLAS, A. S. (1953), F. clin. Path., 6, 23.

5. CREVELD, VAN S., and PAULSSEN, M. P. (1951), Lancet, ii, 242.

6. DODDS, C., and MILLS, G. L. (1959), Ibid., i, 1160.

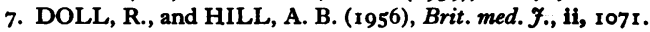

8. DUGUID, J. B. (1946), f. Path. Bact., 58, 207.

9. GARDIKAS, C., TSAKAYANNIS, F., and THOMPOULOS, D. (1959), Acta haemat. (Basel), 21, 129.

10. GOFMAN, J. W. (1959), 'Coronary Heart Disease', Blackwell Scientific Publications Ltd., Oxford.

11. HARRISON, C. V. (1948), f. Path. Bact., 60, 289.

12. HAMMOND, E. C., and HORN (1954), f. Amer. med. Ass., 155, 1316.

13. HEARD, B. E. (1952), F. Path. Bact., 64, 13.

14. INGRAM, G. I., BIGGS, R., and ARMITAGE (1953), 7. clin. Path., 6, 246.

15. LEMPERT, H., and POLLER, L., to be published.

16. MCDONALD, L. (1959), European Congress of Haematology, London, abstract.

17. MCDONALD, L., and EDGILL, M. (1957), Lancet, ii, 457. 18. MORRIS, J. N. (1958), Circulation, 17, 321.

19. OGURA, J. (1946), F. clin. Invest., 25, 486.

20. OWREN, P. (1959), Lancet, ii, 754.

21. PAYLING WRIGHT, G. (1954), 'An Introduction to Pathology', and ed., Longmans, Green and Co. Ltd., London.

22, POLLER, L. (1954), Angiology, 5, 21.

23. POLLER, L. (1956), Clin. Sci., 15, 55.

24. POLLER, L. (1957), f. clin. Path., 10, 348.

25. POLLER, L. (1960), Ibid., 13, 226.

26. POLLER, L. (1959), Ibid., 12, 331.

27. QUICK, A. J. (1935), f. biol. Chem., 109, 83.

28. SPOONER, M., and MEYER, O. O. (1945), F. Lab. clin. Med. 30, 390 .

29. WAUGH, T. R., and RUDDICK, D. W. (1944), Canad. med. Ass. F., 50, 547 .

30. WESSLER, S., BALLER, J. D., and GOLBERT, M. (1956), Э. clin. Invest., 35, 743 .

References continued from page $562-\mathcal{F} . R$. O'Brien, M.A., D.M., M.R.C.S., M.R.C.P.

7. BORN, G. V. R. (1958), Biochem. F., 68, 695.

8. BOUNAMEAUX, Y. (1957), Thromb. Diath. Haem., I, 209.

9. CHANDLER, A. B. (1958), Lab. Invest., 7, 1 ro.

ro. DAWSON, R. M. C., and BANGHAM, A. D. (1959), Biochem. $\boldsymbol{\mathcal { F }}$., 72, 493 .

I I. GORMSEN, J. (1959), Brit. F. Haemat., 5, 257.

12. HUGHES, J. (1953), Arch. int. Physiol., 6r, 565.

13. HUGHES, J. (1959), Thromb. Diath. Haem., 3, 34.

14. LUSCHER, E. F. (1959), Schweiz. med. Wschr., 89, 1021.

15. McDONALD, L., and EDGILL, M. (1959), Lancet, i, 1115.

16. MERSKY, C., GORDON, H., and LACKNER, H. (1960), Brit. med. Э., i, 219.

17. MASTER, A. M., DACK, S., and JAFFE, H. (1939), Amer. Heart $\mathcal{F}, \mathbf{1 8}, 434$.

18. MOOLTEN, S. E. L., VROMAN, L., VROMAN, S., and GOODMÁN, B. (I949), Arch. intern. Med., 84, 667.

19. MUSTARD, J. F. (1958), Canad. med. Ass. F., 79, 554.

20. NILSSON, I. M., BLOMBACK, M., and BLOMBACK, B. (1959), Acta med. scand., 164, 263.
21. NITZBERG, S. I., PEYMAN, A., GOLDSTEIN, R., and PROGER, S. (1959), Circulation (N.Y.), 19, 676.

22. O'BRIEN, J. R. (1958), Lancet, i, 410.

23. O'BRIEN, J. R. (1959), Nature (Lond.), 184, 1580.

24. O'BRIEN, J. R. (1960), unpublished work.

25. POOLE, J. C. F. (1959), Quart. F. exp. Physiol., 44, 377.

26. SAWYER, P. N., PATE, J. W., and WELDON, C. S. (1953), Amer. F. Physiol., 175, 108.

27. SCHWARTZ, S. I. (1959), Surg. Gynec. Obstet., 108, 533.

28. SHARP, A. A. (1958), Brit. F. Haemat., 4, 28.

29. WALDON, A., CHAPMAN, J. E., and EVANS, J. M. (1954), Amer. Heart $\mathcal{F}$, , 47, 563.

30. WRIGHT, H. P. (1942), F. Path. Bact., 54, 461.

31. ZUCKER, M. B., and BORRELLI, J. (1959), F. appl. Physiol., I4, 575 .

32. ZUCKER, M. B., and BORELLI, J. (1960), Thromb. Diath, Haem., 4, 424. 